\title{
Dermatoloji Derneklerinin ve İşlevlerinin İnternet Ortamında İncelenmesi
}

\section{Review of Dermatology Associations and Their Functions on Internet}

\author{
Sevda Gizlenti, Tuğba Rezan Ekmekçi, Şirin Yaşar \\ Haydarpaşa Numune Eğitim ve Araştırma Hastanesi, Deri ve Zührevi Hastalıklar Kliniği, i̇stanbul, Türkiye
}

\section{Özet}

Amaç: Mesleki örgütlenmenin en önemli yapı taşlarından biri de derneklerdir. Bu çalışmada, ülkemizde ve dünyada faaliyet gösteren dermatoloji derneklerinin saptanması ve bunların genel yapısı ile faaliyetlerinin araştırılması amaçlandı.

Gereç ve Yöntem: İnternette arama motoruna (www.google.com) "international, Asian, European, African ve dünya ülkelerinin ve ırklarının isimleri" ile "dermatology, cutaneous, skin, nail, hair, skin biology, cosmetic, laser, photobiology, dermoscopy, teledermatology, dermatoallergy, dermatoimmunology, sexually transmitted disease, dermatovenereology, dermatooncology, dermatosurgery, dermatologic imaging, dermatopathology, psychodermatology" ve "foundation, association, society, organization" anahtar kelimeleri yazılarak Türkiye'deki ve Dünyadaki derneklere ulaşıldı. Web sayfası olup olmaması ve yayın dili açısından dernekler dört gruba ayrıldı. "International League of Dermatology Societies (ILDS) " web sitesine girilerek derneklerin buraya üye olup olmadıkları incelendi. Ayrıca derneklerin tarihçeleri, amaçları, idari yapıları, gelir kaynakları, üye sayıları, üyelik şartları, dernek üyeliklerinin avantajları, eğitim faaliyetleri, süreli yayınları, bilimsel çalışma grupları ve sosyal faaliyetleri incelendi.

Bulgular: Dünyada 194 dermatoloji derneği saptandı. En çok derneği olan ülkeler, Amerika Birleşik Devletleri (22), Türkiye (14), İtalya (11) ve İngiltere (9) idi. Bu derneklerin 53'ü uluslararası, 141'i ulusaldı. Uluslararası dernek sayısı en fazla olan ülkeler ise Amerika Birleșik Devletleri (12) ve Almanya (5) idi. İngilizce web sitesi olan 72, ingilizce ve anadilinde web sitesi olan 17, sadece anadilinde web sitesi olan 53, web sitesi olmayan 52 dernek saptandı. Ülkemizdeki derneklerden sadece birinin İngilizce web sitesi vardı; dört derneğin web sayfası yoktu, hiçbiri uluslararası değildi. ILDS'ye üye dernek sayısı 131'di. Bunların 12 tanesi Amerika Birleşik Devletleri'ne aitti. Ülkemizden ise dört dernek ILDS'ye üyeydi.

Sonuç: Ülkemizdeki dernek sayısı yeterlidir. Ancak uluslararası hüviyet kazanma, mali olarak güçlü yapıya sahiplik, eğitim ve bilimsel faaliyetlerde etkinlik, süreli dergilerin dermatoloji dünyasındaki yeri gibi konularda yolumuzun uzun olduğu söylenebilir. (Türkderm 2011; 45: 66-72)

Anahtar Kelimeler: Ulusal, uluslararası, dermatoloji dernekleri

\section{Summary}

Background and Design: Associations are the most important constituents of occupational organizations. The objective of this study was to determine dermatology associations and to investigate their structures and functions.

Material and Method: Dermatology associations were reached through the internet via a search engine (www.google.com) by entering the keywords "international, Asian, European, African, and the other nationalities and races" and "dermatology, cutaneous, skin, nail, hair, skin biology, cosmetic, laser, photobiology, dermoscopy, teledermatology, dermatoallergy, dermatoimmunology, sexually transmitted disease, dermatovenerology, dermatooncology, dermatosurgery, dermatologic imaging, dermatopathology, physchodermatology" and "foundation, association, society, organization". The associations were classified into four groups according to the entities on the particular website and publication language. Associations were searched on the "International League of Dermatology Societies (ILDS)" website in order to investigate membership status. Furthermore, we investigated history, aim, administrative structure, revenue sources, the number of members, membership requirements and benefits, training activities, periodicals, scientific working groups and social activities.

Yazışma Adresi/Address for Correspondence: Dr. Sevda Gizlenti, Haydarpaşa Numune Eğitim ve Araştırma Hastanesi, Deri ve Zührevi Hastalıklar Kliniği, Üsküdar, Istanbul, Türkiye, E-posta: sevdagizlenti@hotmail.com Geliş Tarihi/Received: 18.06.2010 Kabul Tarihi/Accepted: 30.09.2010

Türkderm-Deri Hastalıkları ve Frengi Arşivi Dergisi, Galenos Yayınevi tarafından basılmıştır. Turkderm-Archives of the Turkish Dermatology and Venerology, published by Galenos Publishing. 
Results: One hundred ninety-four associations worldwide have been determined. The countries with a significant number of associations were the United States of America - 22, Turkey - 14, Italy - 11 and England - 9. Fifty-three associations worldwide were international and 141 were national. The countries with a higher number of international associations were the United States of America - 12 and Germany - 5 . There were 72 associations with an english website, 17 with a website in both english and local language, 53 with a website in only local language, 52 without a website. From Turkey, only one association had a website in english, but none of them were international. The number of ILDS members was 131 and 12 of them were Americans. From Turkey, four associations were member of ILDS.

Conclusion: The quantity of Turkish dermatology associations is sufficient. However, we have a long way to become more efficient in educationalscientific activities and periodicals and to gain international recognition. (Turkderm 2011; 45: 66-72)

Key Words: National, international, dermatology associations

\section{Giriş}

Dernekler; kazanç paylaşma dışında kanunlarla yasaklanmamış belirli ve ortak bir amacı gerçekleştirmek üzere, en az yedi gerçek veya tüzel kişinin, bilgi ve çalışmalarını sürekli olarak birleştirmek suretiyle oluşturdukları tüzel kişiliğe sahip topluluklardır'.

Tüm dünyada belli bir amaçla kurulmuş dermatoloji dernekleri birbiriyle iletişim halinde olabilmek ve dünyadaki derneklerin faaliyetlerini takip edebilmek açısından International League of Dermatology Societies (ILDS) adındaki topluluğa üye olmaktadır. ILDS, Dünya Sağlık Örgütü ile kurumsal bağlantıları olan bir organizasyondur. 1935 yılında kurulan bu topluluğun temel amaçları arasında; tüm dünyadaki dermatoloji dernekleri ile dermatolojinin alanına giren diğer derneklerin iletişimini sağlamak, dermatolojide eğitim ve bilimsel çalışmaların gelişmesini teşvik etmek, dünya çapında tüm dermatologların kişisel ve mesleki iletişim içinde olmasını desteklemek, uluslararası sağlık organizasyonlarında dermatolojiyi temsil etmek, dört yılda bir Dünya Dermatoloji Kongresi'ni (World Congress of Dermatology) düzenlemek yer almaktadır².

Bu çalışmada ülkemizde ve dünyada faaliyet gösteren dermatoloji derneklerinin saptanması ve bunların genel yapısı ile faaliyetlerinin araştırılması amaçlandı.

\section{Gereç ve Yöntem}

Internette arama motoruna (www.google.com) "international, Asian, European, African ve dünya ülkelerinin ve ırklarının isimleri" ile "dermatology, cutaneous, skin, nail, hair, skin biology, cosmetic, laser, photobiology, dermoscopy, teledermatology, dermatoallergy, dermatoimmunology, sexually transmitted disease, dermatovenereology, dermatooncology, dermatosurgery, dermatologic imaging, dermatopathology, psychodermatology" ve "foundation, association, society, organization" anahtar kelimeleri yazılarak Türkiye'deki ve Dünyadaki dermatoloji derneklerine ulaşıldı. Web sayfası olup olmaması ve yayın dili açısından, dernekler ingilizce web sitesi olanlar, hem ingilizce hem kendi anadilinde web sitesi olanlar, sadece anadilinde web sitesi olanlar ve web sitesi olmayanlar olmak üzere dört gruba ayrıldı. ILDS'nin web sitesine girilerek derneklerin buraya üye olup olmadıkları incelendi. Ayrıca, internetten ulaşabildiğimiz dernekler arasından ingilizce web sitesi olan derneklerin web sayfalarından tarihçeleri, amaçları, idari yapıları, gelir kaynakları, üye sayıları, üyelik şartları, dernek üyeliklerinin avantajları, eğitim faaliyetleri, süreli yayınları, bilimsel çalışma grupları ve sosyal faaliyetleri incelendi.

\section{Çalışmanın Kısıtıılıkları}

Çalışmada materyalimiz sadece internet olmuştur. Bu nedenle internette ismen bile yer almayan, ulaşamadığımız derneklerin olması muhtemeldir. Anahtar kelimeler olabildiğince geniş tutulmakla beraber bunlar ingilizce olduğundan ülkelerin kendi anadilinde kurulmuş derneklere ulaşılamamış olabilir.

\section{Bulgular}

Toplam 194 dermatoloji derneği saptandı. En çok derneği olan ülkeler, Amerika Birleşik Devletleri (22), Türkiye (14), İtalya (11) ve İngiltere (9) idi. Yüz doksan dört derneğin 53'ü uluslararası, 141'i ulusaldı. Uluslararası dernek sayısı en fazla olan ülkeler ise Amerika Birleşik Devletleri (12) ve Almanya (5) idi. Kıtalara göre dağılıma bakıldığında en çok dernek Avrupa'da yer almaktaydı. Avrupa'da 79 (\%41), Asya'da 53 (\%27), Amerika'da 48 (\%25), Afrika'da $10(\% 5)$ ve Avustralya'da dört (\%2) dernek saptand $\imath^{2-109}$.

Dernekler, web sayfası olup olmaması ve yayın dili açısından incelendiğinde; ingilizce web sitesi olan 72, hem ingilizce hem kendi anadilinde web sitesi olan 17, sadece anadilinde web sitesi olan 53, web sitesi olmayan 52 dernek saptand I $^{2-109}$.

Ülkemizde ingilizce web sitesi olan tek dernek "Deri ve Zührevi Hastalıklar Derneği" idi. Web sayfası olmayan üç derneğimiz vardı. Bunlar, "Çukurova Dermatoloji Derneği", "Dermatopatoloji Derneği" ve "Dermatokozmetoloji Derneği" idi (Tablo 1). ILDS'ye üye dernek sayısı 131'di. Bunların 12 tanesi Amerika Birleşik Devletleri'ne aitti. Ülkemizden "Deri ve Zührevi HastaIıklar Derneği", "Türk Dermatoloji Derneği", "Türkiye Dermatoveneroloji Derneği" ve "Dermatopatoloji Derneği" ILDS'ye üyeydi (Tablo 1) 2 .

Yetmiş dört dernek, dermatolojideki özgül amaçlara yönelik kurulmuştu. Bu derneklerin dağılımı şöyleydi: dermatocerrahide 13, dermatoonkolojide dokuz, pediyatrik dermatolojide yedi, deri görüntüleme ve kozmetolojide altı, dermatopatoloji ve saç hastalıklarında beş, kontakt dermatit, lazer, fotobiyoloji, pigment bozuklukları, allerji immunoloji, teledermatoloji ve psikodermatolojide üç, tırnak ve cinsel yolla bulaşan hastalıklarda bir. Türkiye'de de alt branşlara yönelik toplam altı dernek vardı (Tablo 1).

Web sayfalarından bilgilerine ulaşabildiğimiz toplam 101 dernekten elde edilen bilgiler aşağıda sunulmuştur.

\section{Kuruluş Tarihleri}

Derneklerin tarihi incelendiğinde bazı derneklerin kuruluşlarının oldukça eskiye dayandığı görüldü. Dünyada kurulan en eski dermatoloji dernekleri; Amerika Birleşik Devletleri, İtalya ve 
Almanya'ya aitti. Bunlar, 1876'da Amerika'da kurulan "American Dermatological Association", 1885'de İtalya'da kurulan "Italian Society of Dermatology" ve 1889 'da Almanya'da kurulan "German Dermatological Society" dernekleriydi,3,5. Türkiye'deki en eski dernek ise 1919 yılında İstanbul'da "Emraz-ı Cildiye ve Efrenciye Cemiyeti" adıyla kurulmuştur. Beş yıl sonra kapanarak 14 Kasım 1930 yılında "Cilt ve Zührevi Hastalıklar Cemiyeti" adında tekrar faaliyete geçmiştir ${ }^{6}$. En son ulusal dernek ise 2008 yılında kurulan "Dermatoonkoloji Derneği"dir?. Ülkemizdeki derneklerin kuruluş tarihleri Tablo 1'de belirtilmiştir.

\section{Amaçları}

Derneklerin ortak amaçları içinde dermatoloji ve alanına giren konularda çalışmalar yapmak ve yapılan çalışmaları desteklemek (araştırma projeleri desteği ile), yeni tedavi yöntemleri geliştirmek, bu yeni metodları ulusal ve uluslararası platformda paylaşmak, bu amaçla kongre ve seminerler düzenlemek, kongrelere katılımı desteklemek, yurtiçi ve yurtdışı eğitim bursu temin etmek, dergi ve kitap çıkarmak yer almaktaydı. Aynı zamanda birçok dernek, web sayfalarını eğitim aracı olarak kullanmakta, böylece dermatolojik hastalıklar ile tedavi ve korunma yöntemleri hakkında toplumu bilgilendirmeyi amaçlamaktaydı. Ayrıca dernekler, ulusal ve uluslararası bilgi alışverişini sağladığı gibi hekimlerin gerek kendi aralarında gerekse de bağlı bulunduğu bakanlık arasındaki iletişimde rol almaktaydılar2-111.

\section{İdari Yapıları}

Derneklerin idari yapısını ise genel başkan, başkan yardımcısı, genel sekreter ve sayman ile diğer kurul üyeleri oluşturmaktaydı. Yönetim kurulu üyeleri 11-13 kişi arasında değişmekteydi²-111.

\section{Gelir Kaynakları}

Derneklerin hepsi vergiden muaf kar amacı gütmeyen organizasyonlardı. Temel gelir kaynakları üyelerin ödediği yıllık aidatlardı. Ayrıca düzenledikleri kongre, kurs gibi programlar, dergi, kitap gibi yayınlar, bağışlar ve sponsor firmalar ile reklam gelirleri yan gelir kaynaklarını oluşturmaktaydı ı-111. Örneğin "New Zealand Dermatological Society" web sitesinde yıllık reklam gelirini 5000 dolar olarak açıklamıştı ${ }^{14}$.

\section{Üyelik Aidat Miktarları}

Çoğu dernek web sitesinde üyelik aidat bilgisine yer vermemişti. Toplam 46 derneğin aidat bilgisine ulaşılabildi. Türkiye'deki derneklerin yıllık aidat miktarı 12-60 TL arasında değişirken yurtdışında üyelik sınıfına göre değişik ücretlendirme uygulanmaktaydı ${ }^{2-109}$. En düşük ücret $30 €(59 \mathrm{TL})$ "Society of Hair Testing" derneğine ait iken; en yüksek aidat miktarı 850 USD (1250 TL) ile "American Academy of Dermatology" derneğine aitti $^{13,15}$. "European Society for Cosmetic and Aesthetic Dermatology", "International Society of Teledermatology" ve "International Dermoscopy Society" dernekleri ise yıllık üyelik aidatı almıyordu ${ }^{16,17,18}$.

\section{Bağışlar}

Tüm dernekler bağış kabul etmekteydi ancak iki dernek bağış miktarını sınıflandırmıştı. "American Society of Dermatopathology" 50,100, 200,1000, 5000 dolar olarak sınıflandırmıştı ${ }^{19}$. "Women's Dermatologic Society" ise şirketler için "platinum angel" (platin melek) $\geq \$ 150$ bin, "guardian angel" (koruyucu melek) >\$100 bin, "angel" (melek) 50 bin, "sustainer" (besleyen, güç veren) 25 bin, "bunefactor" 15 bin, "patron" 10 bin, "sponsor" 5 bin, "contributer" (katkı yapan) 1000, "donor" (bağış yapan) $<1000$ dolar adı altında sınıflandırırken; üyeleri için ise "red rose" >5 bin dolar, "pink rose" 1,000-4,999 dolar, "yellow rose" 500-999 dolar, "white rose" <500 dolar şeklinde sınıflandırmıştı ve bağışta bulunanların açık isimlerine yer verilmiştiti ${ }^{20}$

Üye Sayıları

Üye sayısı sıklıkla belirtilmemiş̧ti. Ancak 42 derneğin üye sayısı ile ilgili bilgilere ulaşılabildi. Üye sayısı 12 (International Society for Skin Imaging-Almanya) ile 16,000 arasında değişmekteydi. En çok üyesi bulunan dernekler "Japanese Dermatologi-

Tablo 1. "Kuruluş yıllarına göre Türkiye'de bulunan dernekler"

\begin{tabular}{|c|c|c|c|c|c|}
\hline Dernek adı & Kuruluş tarihi & Merkezi & Dergi & Web sitesi & íLDS'ye üyelik durumu \\
\hline Deri ve Zührevi Hastalıklar Derneği & 1930 & İstanbul & + & + & + \\
\hline Ankara Deri ve Zührevi Hastalıklar Derneği & 1960 & Ankara & & + & \\
\hline Türk Dermatoloji Derneği & 1968 & Ankara & + & + & + \\
\hline Cüzzamla Savaş Derneği & 1976 & İstanbul & & + & \\
\hline Türkiye Dermatoveneroloji Derneği & 1987 & İzmir & & + & + \\
\hline Çukurova Dermatoloji Derneği & 1991 & Adana & & - & \\
\hline Dermatopatoloji Derneği & 1991 & Ankara & & - & + \\
\hline Dermatokozmetoloji Derneği & 1997 & Bursa & & - & \\
\hline Akdeniz Deri ve Zührevi Hastalıklar Derneği & 1998 & Antalya & & + & \\
\hline Dermatolojik Cerrahi Derneği & 2003 & Ankara & & + & \\
\hline Pediatrik Dermatoloji Derneği & 2004 & Kayseri & & + & \\
\hline Dermatoloji Akademisi Derneği & 2006 & İstanbul & + & + & \\
\hline Dermatoimmunoji Derneği & 2007 & Ankara & & + & \\
\hline Dermatoonkoloji Derneği & 2008 & İzmir & & + & \\
\hline
\end{tabular}


cal Association" $(10,000)$ ve "American Academy of Dermatology" $(16,000)$ idji, $^{9}$.

\section{Üyelik Şartları}

Derneklere üyelik şartları değişiklik göstermekteydi. Çalışmaya alınan derneklerden 17 tanesi özel bir şart belirtmeksizin tüm dermatologları ve derneğin amacına uyan diğer hekimler ile araştırmacıları yıllık aidatı ödeyerek ve web sitesindeki formu doldurarak üyeliğe kabul ediyordu ${ }^{2-109}$. Özel şart olarak derneğin bulunduğu ülkede oturuyor olmak, dernek üyelerinden öneri mektubu getirmek ve board sertifikası sahibi olmak isteniyordu. Türkiye'deki derneklerden sadece "Ankara Deri ve Zührevi Hastalıklar Derneği" yurtdışından üyelik kabul etmekteydi ${ }^{21}$. Hindistan'daki "Indian Association of Dermatologists, Venerologists and Leprologists" ve Avusturalya'daki "Skin and Cancer Foundation" dernekleri yurtdışından üye kabul etmiyordu ${ }^{8,12}$. Board sertifikasını şart koyan dernekler ise "Canadian Dermatology Association", "American Society of Dermatopathology", "Women's Dermatologic Society", "American Society of Cosmetic Dermatology and Aestetic Surgery" ve "Society for Pediatric Dermatology" idi i9,20,22,23,24.

Dernek üyelerinden öneri mektubu isteyen dernekler ise "European Dermatology Forum", "Dermatological Society of Singapore", "Society for Cutaneous Ultrastructural Research", "European Hair Research Society", "North American Hair Research", "European Society for Laser Dermatology" ve "European Academy of Dermatology and Venereology" idi25,26,27,28,29,30,31. Üyelerin Faydalanabileceği Olanaklar

Çoğu dernek, üyelerine kongre indirimi, dergiye ücretsiz veya indirimli ulaşım hakkı, derneğin verdiği burs ve ödül programlarından faydalanma hakkı tanıyordu. Farklı olarak "Dermatological Society of Singapore" derneğinin kongrelerine sadece üyeler katılabiliyordu"2. "European Nail Society" derneği ise üyelerine konusunda otör olmuş hekimlerle olgu tartışma imkanı tanımaktaydı. Ayrıca sadece üyelerin ulaşabileceği derlemeler, olgu sunumları ve literatürler yer almaktaydı ${ }^{40}$.

\section{Eğitim Faaliyetleri}

Dernekler sürekli eğitimi sağlamayı ortak hedef edinmişlerdi. Bu amaçla ulusal ve uluslarası kongre, seminer düzenlemekte ve dergi çıkarmaktaydılar. Eğitimi ve çalışmaları desteklemek amaçlı burs ve ödül programları bulunmaktaydı. "Türk Dermatoloji Derneği" asistan eğitimi açısından "Dermatolojide Kış Okulu" adı altında her yıl Aralık ayında dermatolojik hastalıklar tanı ve tedavisi konusunda seminerler düzenlemekteydi ${ }^{32}$. Ayrıca "Pediatrik Dermatoloji Derneği"de "Yaz Okulu" adı altında eğitim vermekteydi ${ }^{3}$. Benzer eğitim programları yurt dışında da "American Academy of Dermatology", "European Dermatology Forum" ve "Japanese Society for Investigative Dermatology" derneklerinde de bulunmaktayd I $^{13,23,32}$. Ayrıca bazı derneklerin web sitelerinde tedavi kılavuzları, deri hastalıkları resimleri ve hastalıklarla ilgili geniş bilgi yer almaktaydı. Bunlar "American Academy of Dermatology", "New Zealand Dermatological Society", "European Dermatology Forum", "European Society for Laser Dermatology", "British Association of Dermatologists" ve "International Union Against Sexually Transmitted Infections" dernekleriydi ${ }^{13,14,25,30,35,36}$.

\section{Süreli Yayınlar}

Toplam 52 derneğin süreli yayını bulunmaktaydı. Bu yayınlar bilimsel dergi ve "newsletter" isimli dernek üyelerine gönderilen bilimsel çalışma içermeyen dernek haberlerini içeren yayınlardı. Dergilerini yılda üç kez yayınlayan bir dernek, dört kez yayınlayan 15 dernek, 6 kez yayınlayan 8 dernek ve aylık yayınlayan 13 dernek bulunmaktayd $\mathrm{I}^{2-111}$.

Türkiye'de ise "Deri ve Zührevi Hastalıklar Derneği", "Dermatoloji Akademisi Derneği" ve "Türk Dermatoloji Derneği"nin yıl-

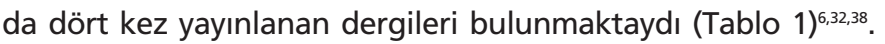
Ayrıca "Dermatoloji Akademisi Derneği" ne ait online İngilizce yayınlanan bir başka dergi "Turkish Academy of Dermatology" de bulunmaktaydı. Türkiye'deki hiçbir derneğin "newsletter" I bulunmamaktaydı.

Genel olarak, yayınlara tüm üyeler ücretsiz ulaşmaktaydı. Dergi için ek ücret talep eden dernekler "European Dermatology Forum" ve "International Society for Dermatologic Surgery" idi25,39.

\section{Bilimsel Çalışma Grupları}

Onbir derneğin web sayfasından bilimsel çalışma grubu olduğu verisine ulaşıldı. Bu dernekler "European Society for Dermatological Research", "Czech Dermatovenereology Society", "Hungarian Dermatological Association", "Italian Society of Dermatology", "Malaysian Dermatological Society", "Bulgarian Dermatological Society", "Skin and Cancer Foundation Australia", "European Society of Contact Dermatitis", "Slovak Dermatovenereological Society" idi 12,41,42,43,44,45,46,47,48. .

Türkiye'den "Deri ve Zührevi Hastalıklar Derneği"nin psoriazis, dermatoonkoloji ve dermatopsikiyatri alanında çalışma grupları, "Türk Dermatoloji Derneği"nin ise Behçet, büllü hastalıklar, kontakt dermatit, dermatopatoloji, yaşam kalitesi, fototerapi, mesleki sorunlar, dermoskopi ve Türk Tabipleri Birliği Uzmanlık Dernekleri Eşgüdüm Kurulu (TTB-UDEK) çalışma grupları bulunmaktayd ${ }^{6,32}$.

\section{Sosyal Faaliyetleri}

Dernekler kongre ve seminerleri aynı zamanda sosyal iletişim araCı olarak kullanmaktaydı ${ }^{2-110}$. Özel etkinlik düzenleyen dernekler "American Academy of Dermatology", "Women's Dermatologic Society" ve Türkiye'den "Cüzzamla Savaş Derneği" idi 13,20,49.

\section{Tartışma}

Ulusal ve uluslararası çok sayıda dernek olmasına rağmen derneklerin genel yapısını ve faaliyetlerini inceleyen bir çalışmaya literatürde rastlanmamıştır. Ülkemizde dermatoloji ve sivil toplum kuruluşlarını araştıran tek bir çalışma bulunmaktadır ${ }^{10}$. Derneklerin tarihçesi incelendiğinde dermatoloji alanındaki ilk derneğin 1876 'da Amerika'da kurulduğu görüldü. Ülkemizde ise dermatoloji derneği ilk kez 1919 yılında kurulmuş, ancak 5 yıl hizmetten sonra kapanmak zorunda kalmıştır. İkinci kez 14.11.1930 tarihinde "Cilt ve Zührevi Hastalıklar Cemiyeti" adı altında İstanbul'da kurulmuştur. Ülkemizde dernek faaliyetlerinin geç başlama nedeni 19. yüzyılda Osmanlı İmparatorluğunun çöküş döneminde olması ve ardından gelen 1. Dünya Savaşı nedeniyle olabilir. Benzer şekilde dünyadaki ülkelerin de 
yaşadıkları savaş dönemlerinde dernek faaliyetleri ve bilimsel çalışmalar açısından olumsuz etkilendiği görülmektedir ${ }^{2,111}$. Uzun bir aradan sonra 1960 yılında Ankara merkezli "Ankara Deri ve Zührevi Hastalıklar Derneği" ve 1968 'de "Türk Dermatoloji Derneği" kurulmuştur. 1990'lı yıllardan sonra ise ülkemizde dernek sayısında giderek artış izlenmiştir.

Ayrıca son yıllarda gerek ülkemizde gerekse dünyada dermatocerrahi, dermatoonkoloji gibi özgül dermatoloji alanlarındaki derneklerin sayısının artması da dikkat çekmektedir.

Dünyada dernek sayısında ülke olarak ikinci sırada çıkmamızda bazı yerel derneklere internetten ulaşamamış olmamızın etkisi olsa da, bu çalışma ile sayısal olarak ülkemizdeki dernekleşmenin yeterli olduğu söylenebilir. Ancak uluslararası hüviyet kazanma, mali olarak güçlü yapıya sahiplik, eğitim ve bilimsel faaliyetlerde etkinlik, süreli dergilerin dermatoloji dünyasındaki yeri gibi konularda, derneklerimiz son yıllarda daha aktif bir çalışma içinde olsa da, bu yolda yolumuzun uzun olduğu açıktır.

\section{Kaynaklar}

1. Dernekler Dairesi Başkanlığı. Dernek Nedir, Nasıl Kurulur. 2009. Available

http://www.dernekler.gov.tr/index.php?option=com_content\&vie $\mathrm{w}=$ category \&layout=blog\&id=37\&ltemid=77\&lang=tr (son erişim tarihi 26.09.2009).

2. International League of Dermatology Societies. 2009. Available at: http://web.ilds.org/cms/index.php?page=societies (son erişim tarihi 30.09.2010)

3. American Dermatological Association. 2009. Available at: http://www.amer-derm-assn.org/about.html (son erişim tarihi 30.09.2009).

4. İtalian Society of Dermatology. 2009. Available at: http://www.sidemast.org/about-sidemast.php (son erişim tarihi 09.10.2010)

5. German Dermatological Society. 2009. Available at: http://www.derma.de/fileadmin/derma/pm_derma_ddg/ddg_en.p df (son erişim tarihi 07.10.2009).

6. Deri ve Zührevi Hastalıklar Derneği. 2010. Available at: http://www.turkderm.org.tr/default.asp (son erişim tarihi 02.06.2010)

7. Dermatoonkoloji Derneği. 2010. Available at: http://dermatoonkolojidernegi.org/ (son erişim tarihi 28.05.2010).

8. Indian Association of Dermatologists Venerologists and Leprologists. 2009. Available at: http://www.iadvl.org/site/?q=node/14 (son erişim tarihi 15.10.2009).

9. Japanese Dermatological Association. 2009. Available at: http://www.dermatol.or.jp/english/history.html (son erişim tarihi 17.10.2009)

10. Korean Dermatological Association. 2009. Available at: http://www.derma.or.kr/eng/index.asp (son erişim tarihi 17.10.2009)

11. Philippine Academy of Clinical and Cosmetic Dermatology. 2010. Available at: http://www.paccd.org.ph/ (son erișim tarihi 12.01.2010).

12. Skin and Cancer Foundation Australia. 2010. Available at: http://www.scfa.edu.au/main-overview.html (son erişim tarihi 12.01.2010)

13. American Academy of Dermatology. 2009. Available at: http://www.aad.org/ (son erişim tarihi 30.09.2009).

14. New Zealand Dermatological Society. 2010. Available at: http://dermnetnz.org/(son erişim tarihi 02.05.2010).
15. Society of Hair Testing. 2010. Available at: http://www.soht.org/html/SoHT.html (son erişim tarihi 14.05.2010).

16. European Society for Cosmetic and Aesthetic Dermatology. 2010. Available at: http://www.escad.org/ (son erişim tarihi 21.01.2010).

17. International Society of Teledermatology. 2010. Available at: http://www.teledermatology-society.org/articles.htm (son erişim tarihi 30.05.2010).

18. International Dermoscopy Society. 2010. Available at: http://www.dermoscopy-ids.org/ (son erişim tarihi 30.05.2010).

19. American Society of Dermatopathology. 2010. Available at: http://www.asdp.org/Home.htm (son erişim tarihi 2.03.2010).

20. Womens Dermatologic Society. 2010. Available at: http://www.womensderm.org/ (son erişim tarihi 12.03.2010).

21. Ankara Deri ve Zührevi Hastalıklar Derneği. 2010. Available at: http://ankaraderm.org/ (son erişim tarihi 30.04.2010).

22. Canadian Dermatology Association. 2009. Available at: http://www.dermatology.ca/ (son erişim tarihi 05.10.2009).

23. American Society of Cosmetic Dermatology and Aestetic Surgery. 2010. Available at: http://www.ascdas.org/ (son erişim tarihi 31.03.2010).

24. Society for Pediatric Dermatology. 2009. Available at: http://www.pedsderm.net/(son erişim tarihi 22.10.2009).

25. European Dermatology Forum. 2009. Available at: http://www.euroderm.org/content/general_introduction.htm (son erişim tarihi 12.10.2009).

26. Dermatological Society of Singapore. 2009. Available at: http://www.dermatology.org.sg/index.htm (son erişim tarihi 18.12.2009)

27. Society for Cutaneous Ultrastructural Research. 2010. Available at: http://www.scur.org/ (son erişim tarihi 29.01.2010).

28. European Hair Research Society. 2010. Available at: http://www.ehrs.org/ (son erișim tarihi 19.02.2010).

29. North American Hair Research Society. 2010. Available at: http://www.nahrs.org/home/ (son erişim tarihi 19.02.2010).

30. European Society for Laser Dermatology. 2010. Available at: http://www.esld.org/index.php?s=1 (son erişim tarihi 17.04.2010).

31. European Academy of Dermatology and Venereology. 2009. Available at: http://www.eadv.org/ (son erişim tarihi 30.12.2009).

32. Türk Dermatoloji Derneği. 2010. Available at: http://www.turkdermatoloji.org/ (son erişim tarihi 30.04.2010).

33. Pediatrik Dermatoloji Derneği. 2010. Available at: http://www.pediatrikdermatoloji.net/ (son erişim tarihi 30.04.2010).

34. Japanese Society for Investigative Dermatology. 2009. Available at: http://www.jsid.org/english/ (son erişim tarihi 01.12.2009).

35. British Association of Dermatologists. 2009. Available at: http://www.bad.org.uk//site/1/default.aspx (son erişim tarihi 07.10.2009)

36. International Union Against Sexually Transmitted Infections. 2010. Available at: http://www.iusti.org/ (son erişim tarihi 24.01.2010).

37. Pan Arab League of Dermatologists. 2009. Available at: http://www.arab-derma.com/(son erişim tarihi 06.10.2009).

38. Dermatoloji Akademisi Derneği. 2010. Available at: http://www.dad.org.tr/ (son erişim tarihi 30.05.2010).

39. International Society for Dermatologic Surgery. 2010. Available at: http://www.isdsworld.com/ (son erişim tarihi 27.02.2010).

40. European Nail Society. 2010. Available at: http://www.euronailsociety.org/(son erişim tarihi 23.04.2010).

41. European Society for Dermatological Research. 2010. Available at: http://www.esdr.org/ (son erişim tarihi 23.04.2010).

42. Czech Dermatovenereology Society. 2010. Available at: http://www.lfhk.cuni.cz/dermat/indexan.htm (son erişim tarihi 23.04.2010)

43. Hungarian Dermatological Association. 2009. Available at: http://www.derma.hu/ (son erişim tarihi 03.11.2009).

44. Italian Society of Dermatology. 2009. Available at: http://www. sidemast.org/about-sidemast.php (son erişim tarihi 14.11.2009). 
45. Malaysian Dermatological Society. 2009. Available at: http://www.dermatology.org.my/ (son erişim tarihi 14.11.2009).

46. Bulgarian Dermatological Society. 2010. Available at: http://www.bg-derm.org/index_eng.html (son erişim tarihi 20.05.2010).

47. European Society of Contact Dermatitis. 2010. Available at: http://www.escd.org/aims/ (son erişim tarihi 25.01.2010).

48. Slovak Dermatovenereological Society. 2010. Available at: http://www.sds-sk.sk/prvaa.htm (son erişim tarihi 13.04.2010).

49. Cüzzamla Savaş Derneği ve Vakfı. 2010. Available at: http://www.cuzzam.org.tr/ (son erişim tarihi 08.04.2010).

50. The Federation of Medical Societies of Hong Kong. 2009. Available at: http://www.fmshk.org/fmshk.php?lang=eng (son erişim tarihi 2.10.2009).

51. The Hong Kong Society of Dermatology \& Venereology. 2009. Available at: http://www.medicine.org.hk/hksdv/home.htm (son erişim tarihi 2.10.2009).

52. European Immunodermatology Society. 2010. Available at: http://www.esdr.org/index.php?option=com_content\&task=view \&id=86\&ltemid=1 (son erişim tarihi 21.03.2010)

53. European Society for Dermatology and Psychiatry. 2010. Available at: http://www.esdap2009.org/ (son erişim tarihi 21.03.2010).

54. European Society for Pediatric Dermatology. 2009. Available at: http://www.espd.info/ (son erişim tarihi 12.12.2009).

55. International Society of Dermatology. 2009. Available at: http://www.intsocderm.org/i4a/pages/index.cfm?pageid=1 (son erişim tarihi 12.10.2009).

56. International Society of Dermatolopathology. 2010. Available at: http://www.intsocdermpath.org/ (son erişim tarihi 03.05.2010).

57. International Society of Pediatric Dermatology. 2010. Available at: http://ispd.actu.com/ (son erişim tarihi 04.05.2010).

58. The Australasian College of Dermatologists. 2009. Available at: http://www.dermcoll.asn.au/public/default.asp (son erişim tarihi 06.12.2009).

59. Irish Association of Dermatologists. 2010. Available at: http://www.irishdermatologists.ie/ (son erişim tarihi 18.01.2010).

60. Maltese Association of Dermatology \& Venereology. 2010. Available at: http://www.madv.org.mt/ (son erişim tarihi 07.01.2010).

61. Philippine Dermatological Society. 2010. Available at: http://pds.org.ph/ (son erişim tarihi 02.01.2010).

62. Slovak Dermato-venereological Society. 2010. Available at:http://www.sds-sk.sk/prvaa.htm (son erişim tarihi 14.03.2010).

63. Dermatological Society of Thailand. 2009. Available at: http://www.dst.or.th/en_contact.php (son erişim tarihi 5.12.2009).

64. Türkiye Dermatoveneroloji Derneği. 2009. Available at: http://trdvd.org/ (son erişim tarihi 11.12.2009).

65. Association of Professors of Dermatology. 2010. Available at: http://www.dermatologyprofessors.org/ (son erişim tarihi 17.02.2010).

66. Society for Investigative Dermatology. 2010. Available at: http://www.sidnet.org/ (son erişim tarihi 14.02.2010).

67. International Academy of Cosmetic Dermatology. 2010. Available at: http://www.iacdworld.org/ (son erişim tarihi 3.02.2010).

68. International Society for Biophysics and Imaging of the Skin. 2010. Available at: http://www.i-s-b-s.org/ (son erişim tarihi 12.01.2010).

69. International Society for Skin Imaging. 2010. Available at: http://www.issi.de/ (son erişim tarihi 25.01.2010).

70. European Society for Dermatology. 2010. Available at:http:// www.esdap2009.org/ (son erişim tarihi 25.01.2010).

71. Australian Hair and Wool Research Society. 2010. Available at: http://www.ahwrs.org.au/ (son erişim tarihi 07.02.2010).

72. International Hair Research Foundation. 2010. Available at: http://www.ihrf.eu/ (son erişim tarihi 07.02.2010).

73. Akdeniz Deri ve Zührevi Hastalıklar Derneği. 2010. Available at: http://akderm.org/ (son erişim tarihi 2.04.2010).
74. American Society for Dermatologic Surgery. 2010. Available at: http://www.asds.net/ (son erişim tarihi 27.04.2010).

75. Egyptian Afro-Asian Society for Cosmetic Dermatology and Laser. 2010. Available at: http://www.ascdl.org/ (son erişim tarihi 12.04.2010).

76. American Society for Mohs Surgery. 2010. Available at: http://www.mohssurgery.org/i4a/pages/index.cfm?pageid=1(son erişim tarihi 27.04.2010).

77. Oman Dermatology Society. 2010. Available at: http://www.omandermatologysociety.com/ (son erişim tarihi 06.05.2010).

78. Dermatological Society of New Jersey. 2010.Available at: http://www.njderm.org/ (son erişim tarihi 17.05.2010).

79. Central East European Dermato Venerological Association. 2010. Available at: http://www.ceedva.ro/?pid=11 (son erişim tarihi 04.02.2010).

80. German Society of Laser Dermatology. 2010. Available at: http://www.ddl.de/en/index.php?\&PHPSESSID=b01c0a24dff3a3cbc efcbdf9b7e3468a(son erişim tarihi 12.04.2010).

81. American Society for Photobiology. 2010. Available at: http://www.pol-us.net/ASP_Home/publications.html (son erişim tarihi 23.03.2010).

82. Argentine Society of Dermatology. 2010. Available at: http://www.sad.org.ar/ (son erişim tarihi 02.04.2010).

83. Asian Society for Pigment Cell Research. 2010. Available at: http://www.aspcr.org/index.html (son erişim tarihi 12.04.2010).

84. The Association of Slovenian Dermatovenerologists. 2010. Available at: http://www.zsd.si/ (son erişim tarihi 04.05.2010).

85. Baltic Association of Dermatovenerologists. 2010. Available at: http://www.badv.lv/ (son erişim tarihi 25.05.2010).

86. Bolivian Society of Dermatology. 2010. Available at: http://www.bago.com.bo/sbd/index.html (son erişim tarihi 15.05.2010).

87. British Photodermatology Group. 2010. Available at: http://www.bpg.org.uk/about/ (son erişim tarihi 20.05.2010).

88. British Society for Dermatological Surgery. 2010. Available at: http://www.bsds.org.uk/ (son erişim tarihi 20.05.2010).

89. The British Society for Dermatopathology. 2010. Available at: http://www.britsocdermpath.co.uk/index.htm (son erişim tarihi 20.05.2010)

90. British Society for Paediatric Dermatology. 2010. Available at: http://www.bspd.org/index.html (son erişim tarihi 20.05.2010).

91. The British Teledermatology Society. 2010. Available at: http://www.teledermatology.co.uk/about1/theconstitution.ashx (son erişim tarihi 27.05.2010).

92. Dermatologic Society Of Greater New York. 2010. Available at: http://dermsociety.org/ (son erişim tarihi 23.05.2010).

93. European Association of Dermato-Oncology. 2010. Available at: http://www.eado.org/index.htm (son erişim tarihi 21.05.2010).

94. European Organisation for Research and Treatment of Cancer Melanoma Group. 2010. Available at: http://www.melanomagroup.eu/content/view/31/43/ (son erișim tarihi 24.05.2010).

95. European Society for Photobiology. 2010. Available at: http://www.esp-photobiology.it/ (son erişim tarihi 27.05.2010).

96. International Dermoscopy Society. 2010. Available at: http://www.dermoscopy-ids.org/ (son erișim tarihi 27.05.2010).

97. European Environmental and Contact Dermatitis Research Group. 2010. Available at: http://orgs.dermis.net/content/ e05eecdrg/ e01members/e125/index_ger.html (son erişim tarihi 25.05.2010).

98. European Society for Pigment Cell Research. 2010. Available at:http://www.espcr.org/index10.php (son erişim tarihi 25.05.2010).

99. European Women's Dermatologic Society. 2010. Available at:http://www.euwds.com/ (son erișim tarihi 26.05.2010).

100. International Society of Teledermatology. 2010. Available at: http://www.teledermatology-society.org/articles.htm (son erişim tarihi 27.05.2010). 
101. Internet Dermatology Society. 2010. Available at: http://www telemedicine.org/ids.htm (son erişim tarihi 27.05.2010).

102. Iranian Society of Dermatology. 2010. http://www.iransocderm. com/portal/index.php (son erişim tarihi 25.05.2010).

103. Mexican Society of Dermatologic Surgery \& Oncology. 2010. Available at: http://www.smcdo.org/index.htm (son erişim tarihi 25.05.2010)

104. PanAmerican Society for Pigment Cell Research. 2010. Available at: http://paspcr.med.umn.edu/ (son erişim tarihi 26.05.2010).

105. Syrian Arab Society of Dermatology.2010. Available at: http://www.sasderm.com/ (son erişim tarihi 26.05.2010).

106. Ukrainian Association of Dermatologist, Venereologists and Cosmetologists. 2010. Available at: http://www.uadvc.org/953/ (son erişim tarihi 27.05.2010).
107. Pakistan Society of Teledermatology. 2010. Available at: http://paktelederm.blogspot.com/ (son erişim tarihi 27.05.2010).

108. International Society for Digital Imaging of Skin. 2010. Available at: http://www.i-s-d-i-s.com/ (son erişim tarihi 27.05.2010).

109. International Society for Biophysics and Imaging of the Skin. 2010. Available at: http://www.i-s-b-s.org/ (son erişim tarihi 27.05.2010).

110. Yürüker Ö, Ekmekçi TR, Köşlü A: Dermatoloji ve Sivil Toplum Kuruluşları. Türkderm 2004; 38: 166-73.

111. Zhang JZ, Zhang XJ: History of the Chinese Society of Dermatology: an overview. Chin Med J (Engl) 2009; 122: 2258-60. 